\title{
Concrete rubble recycling in life cycle contract implementation
}

\author{
Margarita A. Goncharova*, Alexey E. Pankov, Hameed Ghalib Hussain Al-Surraiwyab, and
} Elena $S$. Dergunova

Lipetsk State Technical University, 30 Moskovskaya St. 398055 Lipetsk, Russian Federation

\begin{abstract}
It is known that during the whole life cycle of a building it is necessary to take a responsible approach to the organization and management of construction processes at the present stage of construction. The reasons for the low use of construction waste were analyzed. It is shown that screenings of concrete scrap are the least demanded. The results of researches connected with utilizing concrete scrap to obtain building composites with high functional, economic and environmental efficiency were reflected.
\end{abstract}

\section{Introduction}

Post-industrial information age has come in the modern world development. At the same time, its driving force is industrial innovation, which is based on scientific achievements, the rapid development of new technologies and effective methods of organizing production. Under these conditions, it is necessary to develop new mechanisms for organizing construction that increase the efficiency of design solutions throughout the life cycle of buildings and structures [1,2]. Due to it, the prerequisites for creating competitive advantages of the construction industry will be created.

Nowadays, engineering companies engaged in the organization and management of construction processes throughout the entire life cycle of an object, from investment justification to its liquidation (utilization) are becoming increasingly influential. Such an organization mechanism is known as a engineering procurement construction management (EPCM) or life cycle contracts (LCC). It has been used by project organizations in the case of attracting large investments (especially foreign direct) for a long time.

In Russia, in practice, life cycle contracts are most often found in capital construction. It is known that EPCM cover the entire life cycle of a building or construction, thereby creating conditions for the use of building innovations. The need to apply efficient building composites and innovative technologies for their production is laid in the concept of this mechanism. Cost-effectiveness directly depends on minimizing of operational and postoperational costs, that is, on the quality of the project. This motivation is clear to the executors (project organizations).

Indeed, until recently, building only created a technogenic environment that is necessary to ensure the conditions for the survival of mankind. In contrast to the natural environment,

\footnotetext{
* Corresponding author: magoncharova777@yandex.ru
} 
the artificial environment was protected from external aggressive influences. Today we are only thinking about the impact of human activities (construction is a powerful anthropogenic impact factor) on the environment. The influence of anthropogenic factors in construction activities is reflected in all stages of the life cycle of objects (starting with the extraction of natural raw materials for the production of building products and ending with the recycling (or disposal) of construction wastes). This impact differs both in the nature of the impact and in the level of influence on the environment [3-7].

At the same time, we must not forget that the amount of construction waste such as brick, concrete and reinforced concrete scrap is continuously increasing. Such waste is partially recycled at the crushing and screening equipment. After crushing and fractionation construction waste you can obtain concrete recycling (crushed concrete) in the form of rubble, sand and crushing screenings (concrete dust). Recycled concrete in modern construction should be considered a tough alternative to traditionally used natural inert materials made of stone raw materials [8-9].

Today it is already obvious that the most significant and at the same time unclaimed reserve for minimizing material and energy costs in the construction of buildings and structures are areas related to the use of construction waste in the form of recycled concrete.

All over the world the main housing stock is exposed to moral and physical deterioration (systemic factors), natural disasters and other man-made and natural phenomena, and substandard reinforced concrete products are produced at factories and construction sites. In this regard, the problem rational using of waste construction complex in the concrete materials and products technology was particularly serious. This is facilitated by the widespread introduction of equipment for the processing of such raw materials by mechanical methods $[10,11]$.

\section{Research objective}

The issue of processing of crushed concrete attracted the attention of researchers all over the world in the 1970s and 1980s. The paper "Recommendations for the use of products of processing of non-conditioned concrete and reinforced concrete products" was published in 1984. B.V. Gusev and V.A. Zagursky published the monograph "Recycled Concrete" in 1988. B.A. Krylov, O.A. Lipei, S-A.Y. Murtazaev, M.S. Saidumov, A.Z. Efimenko, A.S. Pilipenko and other scientists researched properties and technologies of heavy compression which include aggregates of crushed concrete. Papers of Russian (Yu.M. Bazhenov, V.I. Solomatov, P.G. Komokhov, E.M. Chernyshov, P.P. Budnikov, V.D. Glukhovsky) and foreign (D.M. Roy and G.R. Gode) scientists devoted to extensive research in the use of industrial products in the production of building materials.

Recycling of concrete in Russia is applied extremely limited. It is explained by the fact that such technogenic raw materials have been little studied. Effective ways of raw materials processing, storage and sorting have not been proposed, there are no universal approaches to the development of compositions and properties of materials based on them [9-11]. But today it has become obvious that the production of recycling concrete is only increasing, therefore, man-made materials constitute an alternative to traditional designs made of natural raw materials.

Recently, studies have emerged in which recycled rubble made of crushed concrete found reasonable applications. The lack of standard technical documents is also an obstacle to the widespread use of such man-made materials. Nevertheless, there are technological methods thanks to which crushed concrete and its screenings can be used in a wide range of building materials: concrete, mortars, hydraulic multicomponent binders.

There are reasons for not being in demand for crashed concrete in building technologies, namely: the specific state and composition, the difference in technogenic raw materials in 
strength indicators, particle size distribution, the absence (or presence) of contaminants, the content of flakiness grains and the content of weak grains.

With an volume of construction production increase, the volume of raw materials for the production of products and structures is increase too. The building complex is the most material-intensive and capital-intensive industry. It annually consumes a huge amount of material resources (raw materials, semi-finished products, energy, water resources), which significantly changing the external environment. The technological process of crushed stone production at the crushing-and-sorting complexes is accompanied by the formation of crushing screenings.

Analysis of literary sources showed that crushing screenings do not find wide practical application yet. Therefore, it is delayed in the territory of the crushing-and-sorting complexes. It leads to a significant pollution of urban ecology due to the content of the socalled stone flour in its composition (particles less than $0.16 \mathrm{~mm}$ in an amount up to $30 \%$ ).

The results of leading scientific directions are studied and analyzed to hypothesize about the possibility of producing concrete composites with improved properties made of screenings crushing concrete scrap and various rocks [7, 8 - 11].

Based on the above, the task has been set. It is required to obtain building composites with optimal construction and technical properties made of screenings crushing concrete scrap. It can be done through using of technological methods, including methods of mechanical activation of curing systems.

The aim of the study is to develop scientifically based methods to produce construction composites. It based on using screenings of crushed concrete scrap.

In accordance with the purpose of the study, the following tasks should be solved:

- the mechanism of action of chemical additives on the process of structure formation of curing systems obtained using screenings of crushed concrete scrap has been studied;

- the composition of composites using screenings crushing concrete scrap has been optimized the structure and properties of the developed composites has been investigated.

\section{Description of investigations}

The forecast of the construction and technological potential of concrete crushing waste made it possible to establish that it can serve as the basis for curing systems. The analysis of papers on crystal chemistry and thermodynamics, of V.F. Zhuravlev's ideas on binding properties demonstrated by compounds of alkaline-earth metals with various oxides, of research within P.I. Bozhenov's, Yu.M. Butt's, A.V. Volzhensky's scientific schools made it possible to prove that metallurgical technogenic waste can be used to synthesize cementing substances and to form curing systems.

When CS on the basis of waste are formed, the main factors for determining the properties of such materials are systematized and a system of factors for controlling and regulating the construction and technical properties of CS is created (see Fig. 1).

The presence crushed concrete scrap in the screening along with minerals and cement hydration products (quartz, calcite, ettringite, dicalcium aluminate, tetracalcium aluminoferrite, etc.) unhydrated Portland cement in an amount of $4 \%$ by weight, which is about $30 \%$ by weight of the original Portland cement, confirms that the hypothesis is true.

These results were taken as the basis for the production of multicomponent binders using the screening of crushing of concrete scrap as an active microfiller.

The activity of fine fillers in plastic remolding did not exceed $2 \mathrm{MPa}$. It was decided to investigate its activity on the test cylinder with a $50 \mathrm{~mm}$ high and the same diameter, made of aggregate with low water and cement ratio $(0.12,0.14$ and 0.16$)$ to improve the strength 
characteristics. The remolding of samples was carried out in three ways: with counterweight, with the help of a small device of Conjugation for the standard consolidation of concrete and forming under pressure (pressing). Samples were air storage for 7 days at a temperature of $18 \ldots 20^{\circ} \mathrm{C}$. After that it was placed for 18 days in a moist air cabinet with a humidity of at least $95 \%$. Then it was saturated with water at room temperature for 2 days. Water-saturated samples were tested at 28 days old on a hydraulic press.

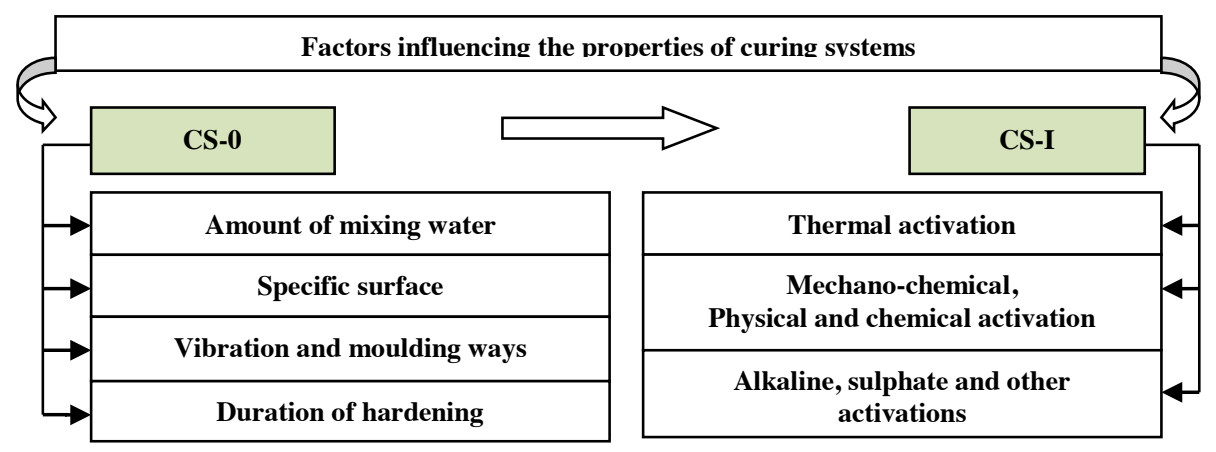

Fig. 1. Ways of influencing curing systems based on concrete scrap

According to the results of the study, concrete scrap with additional grinding to a specific surface of more than $300 \mathrm{~m}^{2} / \mathrm{kg}$ exhibits the properties of a low activity binding agent. This is due to the "awakening" of unhydrated cement and the reactivity of the carbonates in the screening. The test results are shown in Fig. 2.

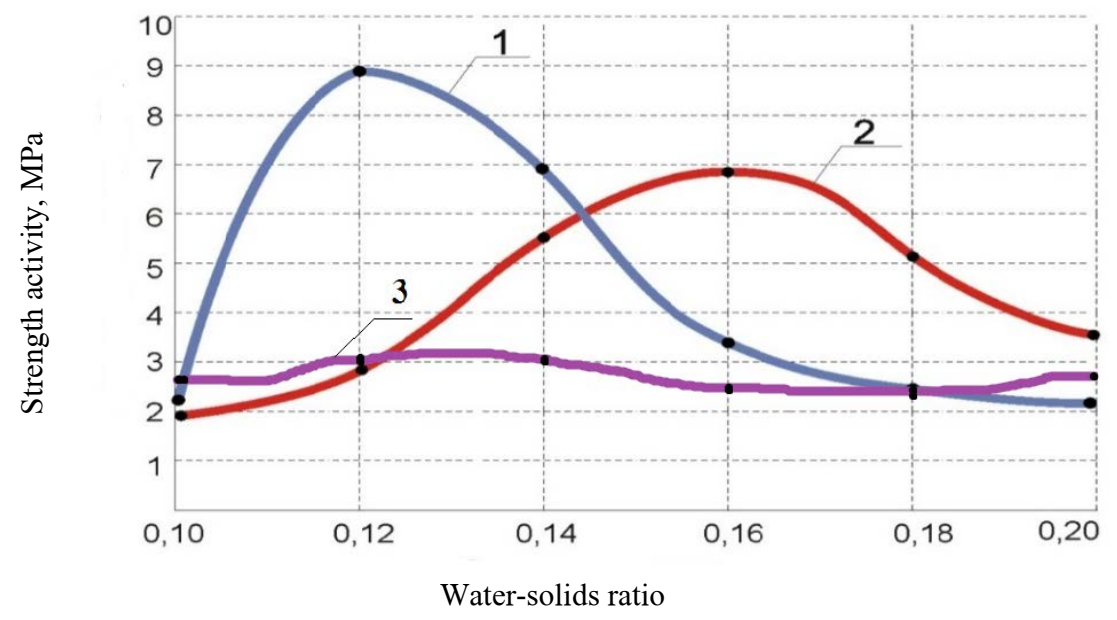

Fig. 2. The dependence of the activity of curing systems based on concrete scrap on the amount of gauged water during powder shaping: 1 - remolding was carried out on a small SoyuzDorNII device with impact compaction, 2 - formation of samples with counterweight, 3 - forming under pressure (pressing).

As a result, curing systems were obtained. The strength of curing systems reaches 9 $\mathrm{MPa}$. The average equivalent diameter of intergranular pores has decreased due to compression of the samples. In this way capillary condensation of moisture has become possible and strength has increased. The appearance of capillary condensation of moisture 
stimulated hydration processes. The hydration processes increased adsorption and condensation phenomena.

Based on the test results (Fig. 3) of the samples for molding under counterweight, the following conclusions can be drawn. The increase specific surface of the converter slag did not lead to a significant increase strength of the samples.

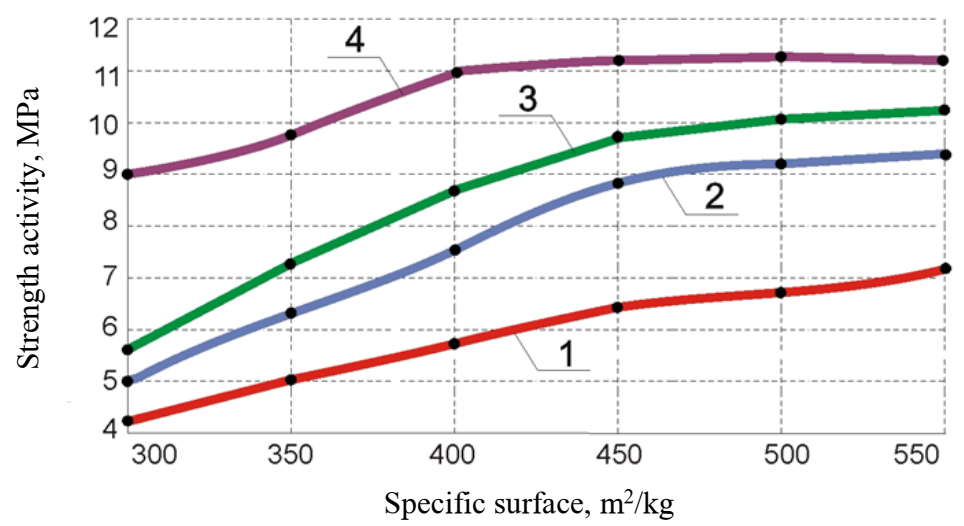

Fig. 3. The effect of fine grinding of converter slags on the activity of the formed curing systems: 1 semidry shaping with compaction by impact, hardening in the aquatic environment; 2 - forming samples with counterweight, hardening in the aquatic environment; 3 - semidry shaping with impact compaction, hardening in air dry conditions; 4 - forming samples with counterweight, hardening in air dry conditions.

The hardening of the system was more intense at a later terms. The maximum strength of the samples when air curing was 4.9 $\mathrm{MPa}$ and maximum strength of the samples when aquatic curing was 10.2 MPa. These results indicate a possible lack of water for the hydration of the active minerals of the converter slag when air hardening of concrete. Grinding slag to a specific surface of $400 \ldots 450 \mathrm{~m}^{2} / \mathrm{kg}$ gave the most significant increase in the strength of the samples (by 1.6-1.7 times, depending on the hardening conditions). A further increase degree of fineness contributed to the growth of the strength activity of the converter slag only by $6 \ldots 8 \%$. Thus, a further increase in the fineness of grinding was considered inexpedient.

\section{Conclusion}

The best results were obtained when testing well compressed samples solidified in the aquatic environment.

Further studies have shown that plasticizers "BIO-NM" and "PFM-NLC" contributed to the growth of the strength activity of ground screenings of concrete scrap. Increasing the strength of the samples ranged from 5 to $25 \%$. The maximum value of strength was achieved with the introduction of the complex mineral and chemical additive "BIO-NM" (12 MPa).

Thus, on the basis of scientific concepts, as well as a result of the implementation of an integrated approach, hardening systems of different levels were obtained. The strength activity of the systems ranges from 3 to $43 \mathrm{MPa}$. Various techniques are used in their synthesis (from activation of the binding properties of technogenic raw materials to mechanical mixing with traditional binders). It has been established that crushed concrete aggregate, that have a partial or continuous shell on the surface of its grains of crushed concrete, influences the process of forming both the structural characteristics of the cement stone and the dense metamorphic aureole between them. The structure of concrete 
composites is characterized by less water absorption (up to 5\%) and the presence of fairly small and uniformly sized pores.

As a result, the possibility of producing construction composites of the B25 strength class based on the screening of concrete scrap crushing was substantiated. Thus, the current stage of construction development is not conceivable without taking into account the theory of the full life cycle of buildings and structures. Thus, buildings' life cycle consist of the design and implementation phase of the project. The project implementation involves construction, operation stage, including current and capital repairs, modernization stage or technical re-equipment, and, most importantly, the stage of dismantling (or disposal) of the facility. Dismantling and disposal stage was not received enough attention until recently. Particularly little attention was paid to the issue of disposal of waste demolition, namely the formation and use of recycled products in construction (Fig. 4).

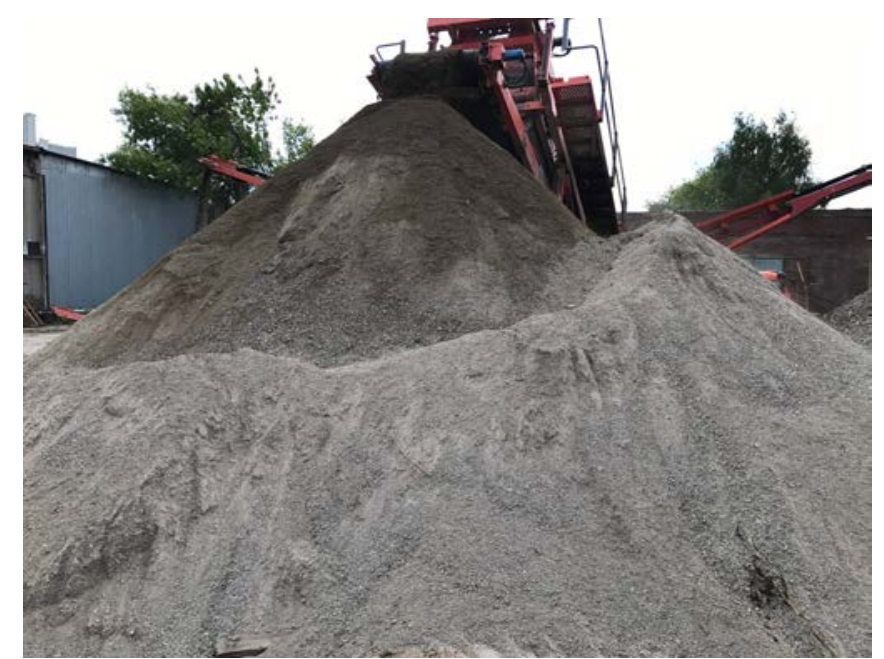

Fig. 4. Construction waste recycling (Lipetsk)

Creating a regulatory structure for getting aggregates from concrete scrap would be the best result of the formulated problem. Besides, finding wide opportunities for using crushing screenings in composites will have a positive impact.

\section{References}

1. J.-E. De Bettignies, T.W. Ross, Public - private partnerships and the privatization of the finance function: An incomplete contracts approach, International Journal of Industrial Organization, V. 27 (3), pp. 358 - 368 (2009)

2. H. Dimitriou, E. J. Ward, Ph. G. Wright, Mega transport projects - Be-yond the 'iron triangle': Findings from the OMEGA research programme, Progress in Planning, V. 86, pp. 1 - 43 (2013)

3. O. Sengul, Mechanical properties of slurry infiltrated fiber concrete produced with waste steel fibers, Construction and Building Materials, V. 186, pp. 1082-1091 (2018)

4. M.A. Goncharova, O.V. Karaseva, S.V. Maklakov, K.V. Bakhaev, Refractory materials for steel-making equipment lining, Journal of chemical technology and metallurgy, V. 53, pp. 636-641 (2018)

5. J. Lee, Sh. Mahendra, P.J.J. Alvarez, Nanomaterials in the construction industry: a review of their applications and environmental health and safety considerations, ACS NANO, V. 7, pp. 3580-3590 (2010) 
6. O. Sengul, Mechanical behavior of concretes containing waste steel fibers recovered from scrap tires, Construction and Building Materials, V. 122, pp. 649-658 (2016)

7. A. Moustafa, M. A. ElGawady, Mechanical properties of high strength concrete with scrap tire rubber, Construction and Building Materials, V. 93, pp. 249-256 (2015)

8. F. M. Z. Hossain, Md. Shahjalal, K. Islam, M. Tiznobaik, M. S. Alam, Mechanical properties of recycled aggregate concrete containing crumb rubber and polypropylene fiber, Construction and Building Materials, V. 225, pp. 983-996 (2019)

9. M. Fisonga, F. Wang, V. Mutambo, Sustainable utilization of copper tailings and tyrederived aggregates in highway concrete traffic barriers, Construction and Building Materials, V. 216, pp. 29-39 (2019)

10. S. Roy, T. Miura, H. Nakamura, Y. Yamamoto, Investigation on applicability of spherical shaped EAF slag fine aggregate in pavement concrete - Fundamental and durability properties, Construction and Building Materials, V.192, pp. 555-568 (2018)

11. Yi Jiang, T.-C. Ling, C. Shi, S.-Y. Pan, Characteristics of steel slags and their use in cement and concrete - A review, Resources, Conservation and Recycling, V. 136, pp. 187-197 (2018) 